\title{
Reduction of marine sediment oxygen uptake: pre-treatment for the determination of infaunal respiration rates
}

\author{
H. M. Golde*, M. P. Crosby**, C. R. Lovell, S. E. Stancyk \\ Marine Science Program and The Belle W. Baruch Institute for Marine Biology and Coastal Research, University of South Carolina, Columbia, \\ South Carolina 29208, USA
}

\begin{abstract}
Biological oxygen demand (BOD) in samples of sandy marine mud sediments from North Inlet, South Carolina, USA, was significantly reduced by irradiating sediment samples with $66240 \mathrm{cGy}$ of ionizing radiation from a cesium137 gamma source. Chemical oxygen demand (COD) was significantly reduced by bubbling ambient air through the sediment for 6 to $10 \mathrm{~h}$. Combined treatments lowered the sediment oxygen uptake to a level which was not statistically different $(p<0.0001)$ from $0.2 \mu \mathrm{m}$ filtered seawater. The described method is useful for sufficiently reducing sediment. oxygen consumption ( $\mathrm{BOD}$ and $\mathrm{COD}$ ) to measure respiration of infaunal organisms, including ophiuroids, bivalves and polychaetes, in a more natural, buried setting.
\end{abstract}

KEY WORDS: Respiration - Marine sediment Infaunal organisms - Biological oxygen demand . Chemical oxygen demand

Measurement of oxygen uptake by infaunal organisms may be performed by either removing the organism from the sediment or not. Infaunal organisms may behave quite differently when removed from their natural sediment. It may therefore be advantageous to measure their respiration while they are in sediment. However, if the organism is left in the sediment during oxygen consumption measurements, the oxygen consumption of the sediment must be accounted for and subtracted. As sediment oxygen uptake can be quite variable and mask the respiration of small organisms, it is advantageous to reduce the sediment oxygen uptake as much as possible in order to assess the test organism's respiration.

\footnotetext{
Present addresses

- National Oceanic and Atmospheric Administration, Sanctuaries and Reserves Division, 1305 East West Highway, 12th Floor, Silver Spring, Maryland 20910, USA

- National Oceanic and Atmospheric Administration, Office of Ocean and Coastal Resource Management, 1305 East West Highway, 11th Floor, Silver Spring, Maryland 20910, USA
}

Oxygen uptake by sediment usually is thought to consist of 2 components: biological oxygen demand (BOD), respiration by both aerobic heterotrophs and chemolithotrophs in the sediment, and chemical oxygen demand (COD) from the oxidation of reduced sediment constituents (Dale 1978). To reduce overall oxygen consumption, both of these components should be reduced.

Although BOD typically is removed by treating the sediment with formalin or formaldehyde (Hargrave 1969, 1972, Dale 1978, Dye 1983, Montagna et al. 1986), this technique is inappropriate for biological investigations which require the re-introduction of animals into the sediment. In addition, the slow diffusion of the chemical treatment into the sediment may not kill deep-dwelling organisms (Dale 1978). Formalin and formaldehyde may also react with oxygen and yield an elevated COD (Pamatmat 1977, Dye 1983).

Gamma irradiation affords a better way to reduce the sediment BOD, killing the organisms, but causing minimal changes in the sediment chemical makeup (Bowen \& Rovira 1961, McLaren 1969). Gamma irradiation has been used to sterilize soil (Lawrence 1956, Bowen \& Rovira 1961, McLaren 1969, Powlson \& Jenkinson 1976. Jakobsen 1984, Griffiths 1987 ) and food (Josephson \& Peterson 1982, Urbain 1986), as well as aquatic sediments (Sansone et al. 1987, Östlund et al. 1989). COD can also be reduced if sufficient oxygen is introduced to the sediment for oxidative reactions to reach an end point.

The purpose of this study was to develop a rapid and simple technique to reduce the sediment oxygen uptake of sandy marine mud by reducing the 2 components, BOD and COD. Techniques described here are useful for treating sediment prior to respiration measurements of infaunal organisms in their natural sediment habitat. 
Materials and methods. Preparation of sediment samples: Sediment was collected at low tide from Debidue Creek, North Inlet, Georgetown County, South Carolina, USA $\left(37^{\circ} 20^{\prime} \mathrm{N}, 79^{\circ} 10^{\prime} \mathrm{W}\right)$. Sediment was sieved through a $2 \mathrm{~mm}$ mesh sieve to remove large macrofauna, mixed by hand, and packed into $7.6 \mathrm{~cm}$ long, $3.8 \mathrm{~cm}$ diameter pieces of polyvinylchloride (PVC) pipe. Each pipe piece containing sediment was capped at both ends with a PVC end cap and sealed with 2 layers of silicon caulking.

Sediment samples were irradiated for $1 \mathrm{~h}$ at the Medical University of South Carolina in Charleston, with an M-38 Gammator (Isomedix, Inc., Parsippany, NJ, USA), which uses a Cesium-137 gamma source $\left(1104 \mathrm{cGy} \mathrm{min}^{-1}\right)$. This yielded a total received dose of $66240 \mathrm{cGy}$.

To reduce COD, the irradiated sediment samples were thoroughly aerated prior to use. Previously irradiated samples (samples were irradiated up to 3 mo prior to aeration) were opened by removing the cap from one end, and placed in a small aquarium (4 l). The aquarium was filled with $0.2 \mu \mathrm{m}$ filtered seawater so that the water level was 2 to $4 \mathrm{~cm}$ above the top of the sample. A $3.8 \mathrm{~cm}$ diameter, $6 \mathrm{~cm}$ long PVC coupler was placed over the open end of each sample so that the water level was about halfway up the side of the coupler. The sediment and water in each sample were mixed into a homogenous slurry using a glass stirring rod. A sterile, cotton-plugged, $1 \mathrm{ml}$ serological pipet, connected with Tygon tubing to an air pump, was used to bubble air through the slurry in each sample for 6 to $10 \mathrm{~h}$. To reduce contamination of the aerating sediment, the aquarium, PVC coupler and glass stirring rod were all rinsed with $70 \%$ isopropyl alcohol and allowed to dry before use.

Following aeration, the pipets were removed from the samples and the sediment was allowed to settle overnight ( 8 to 12 h). Plastic film (Saran Wrap, DowBrands, Indianapolis, IN, USA) was placed over the top of the aquarium to keep foreign matter from falling into the samples during the settlement period.

Measurement of oxygen consumption: Oxygen consumption measurements of treated samples were made using a modification of the methods of Bayne et al. (1977). Each respiration chamber was made from two 1 I glass beakers, modified so that one beaker made the body, and the other the lid of the chamber. The bottom half of the chamber contained a Plexiglass plate with holes drilled in it and supported by short legs, under which a magnetic stir bar was placed. The design was such that a sample sitting in the chamber would have complete water flow around it. The top half of the chamber had 2 ground-glass fittings containing in- and outflow tubes, each of which had a 3-way stopcock. Thus water, continuously flowing through these tubes, could be directed through the chamber or to bypass the chamber, effectively sealing the chamber. The center of the chamber lid had a hole through which an oxygen probe was inserted.

Respiration chambers were placed in a semirecirculating seawater system containing aerated, $0.2 \mu \mathrm{m}$ filtered seawater from a nearby tidal creek. Once water had flowed through a sample chamber it was discarded. The partial pressure $(\mathrm{mm} \mathrm{Hg}$ ) of oxygen in the water inside the respiration chamber was measured using a Radiometer E5046 $\mathrm{pO}_{2}$ electrode (Radiometer USA, Cleveland, $\mathrm{OH}$ ) connected to a Strathkelvin model $781 \mathrm{~B}$ oxygen meter (Strathkelvin, Scotland, UK). Readings were continually recorded on a Kipp \& Zonen BD 41 dual-channel chart recorder.

The sediment sample, in which oxygen consumption was to be measured, was placed inside the respiration chamber. The chamber was completely filled with water, ensuring that there were no trapped air bubbles, placed in the water bath over a stir plate, and the $\mathrm{pO}_{2}$ probe was inserted through the hole in the top of the chamber. The sediment sample was allowed to equilibrate in the chamber for approximately $30 \mathrm{~min}$ while water was flowing through the chamber at $50 \mathrm{ml}$ $\min ^{-1}$ and the stir bar was stirring at a moderately slow rate. Once the chamber exhibited no change in $\mathrm{pO}_{2}$ for at least $10 \mathrm{~min}$, the inflow and outflow valves were closed. The sample was left in the sealed chamber for approximately $1 \mathrm{~h}$ and the decrease in oxygen tension was continually recorded. Approximately every $10 \mathrm{~min}$ readings of the time and exact amount of oxygen in the sample were also recorded. Temperature and salinity of the outflowing water were measured at the onset of each measurement.

Oxygen consumption for the entire chamber was calculated using the formula of Bayne et al. (1985), with the assumption that the barometric pressure at sea level remained constant at $760 \mathrm{~mm} \mathrm{Hg}$ for the duration of the experiment. Oxygen consumption $\left(V_{\mathrm{O}_{2}}\right)$ was also determined for seawater in a control chamber containing only the inflowing seawater. Control $V_{\mathrm{O}_{2}}$ was subtracted from $V_{\mathrm{O}_{2}}$ of a chamber with a sediment sample to obtain the oxygen consumption rate of the sediment only.

Experimental design: To ensure that $1 \mathrm{~h}$ of irradiation was sufficient to significantly reduce biological oxygen demand, samples were initially irradiated for 1 (66240 cGy), 2 (132480 cGy), 3 (198720 cGy) and $4 \mathrm{~h}$ (264960 cGy), and their oxygen consumption measured.

To determine whether the treatment of the sediment samples significantly decreased their oxygen consumption, measurements were made on samples of untreated sediment, samples which had been irradi- 
ated only and samples which had been irradiated and aerated. Oxygen consumption of a chamber containing only $0.2 \mu \mathrm{m}$ filtered seawater was used for comparison. The results of these trials were compared using Analysis of Variance (model: $\mathrm{O}_{2}$ uptake rate = treatment, $\mathrm{n}=6$ to 20 , depending on treatment; Sokal \& Rohlf 1981).

Infaunal ophiuroids (Microphiopholis gracillima) were placed in irradiated, aerated sediments to determine if infaunal organisms could establish themselves in treated sediments.

Results. Initial measurements on 4 samples which were irradiated for $1,2,3$ or 4 h had oxygen uptake rates of $1.2,2.6,1.0$ and $1.2 \mu \mathrm{O}_{2} \mathrm{ml}^{-1}$ sediment $\mathrm{h}^{-1}$, respectively. As there was no obvious difference or pattern in oxygen uptake rate relative to irradiation time, all subsequent irradiation was done for $1 \mathrm{~h}$.

Mean values of oxygen uptake by the different sediment treatments and $0.2 \mu \mathrm{m}$ filtered seawater are shown in Fig. 1. Irradiation of the sediment significantly $(\mathrm{p}<0.0001)$ decreased the sediment oxygen uptake by $55.5 \%$, with the mean value being reduced from $5.68(\mathrm{SE}=2.10)$ to $2.53 \pm 1.74 \mu \mathrm{l} \mathrm{O} \mathrm{ml}^{-1}$ sediment $\mathrm{h}^{-1}$. This difference in sediment oxygen uptake between unirradiated and irradiated sediment represents the BOD. Aerating the sediment decreased the sediment oxygen consumption an additional $89.1 \%$ to a mean value of $0.275 \pm 0.511 \mu \mathrm{O}_{2} \mathrm{ml}^{-1}$ sediment $\mathrm{h}^{-1}$. The difference between irradiated and irradiatedaerated sediment represents COD. Oxygen consumption rates of irradiated-aerated samples were not significantly different $(p<0.0001)$ from those of $0.2 \mu \mathrm{m}$ filtered seawater, which had a mean oxygen uptake of $0.111 \pm 0.040 \mu \mathrm{l} \mathrm{O}_{2} \mathrm{ml}^{-1}$ water $\mathrm{h}^{-1}$.

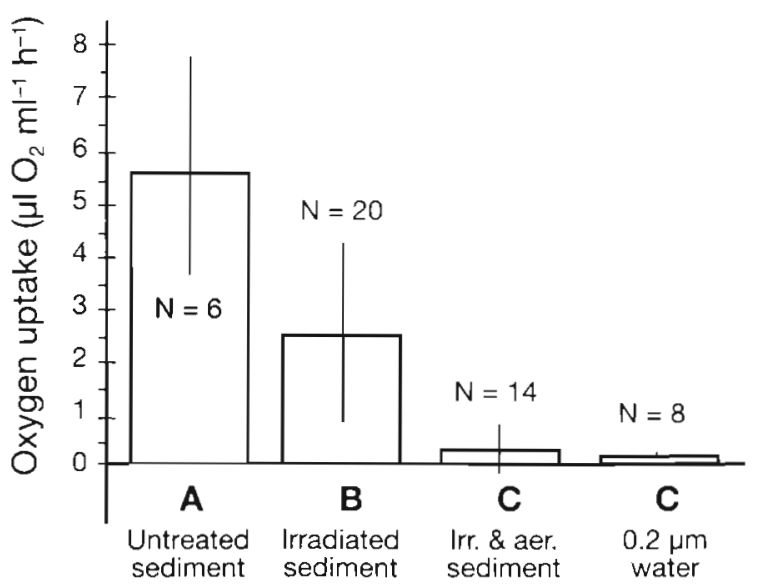

Fig. 1. Mean respiration rates of filtered water and treated sediment samples. Error bars show standard errors of the mean. Treatments with the same letter showed no significant differences between oxygen uptake rates as determined by analysis of variance
Infaunal ophiuroids, which were added to the sediments following aeration, established themselves in the treated sediments. After several hours in the treated sediment, individual ophiuroids had built burrows which appeared identical to those burrows built in untreated sediment. Several small holes surrounded by a small mound of displaced sediments were visible on the surface of each sample. Two, or occasionally 3 , arms were extended out of the holes and waving in the water column or moving across the sediment surface. When individuals were removed from the sediment samples a complete and characteristic burrow system could be seen in the sediment. As it was impossible to distinguish ophiuroid-occupied treated sediment samples from ophiuroid-occupied untreated sediment samples, it appeared that Microphiopholis gracillima behaved in a normal characteristic fashion in the irradiated and aerated sediments.

Discussion. This research demonstrates that $1 \mathrm{~h}$ of ionizing radiation (66240 cGy) reduces sediment oxygen uptake significantly, presumably by reducing BOD. In our study this sediment BOD accounted for $55.5 \%$ of total sediment oxygen demand. The dose used to irradiate sediment in this study is markedly lower than those previously used to sterilize terrestrial soil [2.5 kGy (Jakobsen \& Andersen 1982) to $50 \mathrm{kGy}$ (Griffiths 1987)] and aquatic sediments [5 to $12 \mathrm{kGy}$ (Östlund et al. 1989); 25 kGy (Sansone et al. 1987)], but is closer to that used for food sterilization, which ranges from 50 to $5000 \mathrm{~Gy}$ (Urbain 1986). An average medical $X$-ray (dental or chest $X$-ray) yields a received dose of 0.3 to 5 cGy (Gofman 1981).

The level of ionizing radiation needed for the sterilization of any substance depends on various factors including the types of organisms in the substrate, as well as the level of colonization (Cawse 1975). Because a natural population is made up of a mixture of different species of microorganisms, calculation of the dose needed to sterilize a given soil sample is virtually impossible (Davis et al. 1956).

The amount of water in the soil also affects the level of radiation required to achieve sterility. Soil samples which are damp require less radiation than dry soil to kill the same organisms. This is due to indirect damage to microbial cells from the breakdown products of the radiolysis of water: specifically, highly reactive free radicals such as $\mathrm{OH} \cdot \mathrm{H} \cdot \mathrm{and} \cdot \mathrm{HO}_{2}$ (Cawse 1975 , Ostlund et al. 1989). As the sediment samples in this study were saturated with water, one would expect them to required significantly lower doses of radiation than dry soil to achieve sterility. However, Östlund et al. (1989) and Sansone et al. (1987) used higher doses of radiation to sterilize saturated sediments than Jakobsen \& Andersen (1982) used for soils. Östlund et al. (1989) did not test any levels of radiation lower than 
5 kGy. In this study we did not test whether our sediments were sterile, as we reached our objective of significantly reducing sediment oxygen uptake which could mask subject infaunal respiration.

COD accounted for $44.5 \%$ of total sediment oxygen demand in this study, which is similar to values reported by Cawse (1975) for soil and by Teal \& Kanwisher (1961) and Hargrave (1972) for marine and aquatic sediments. COD may have several components. Skou (1962) postulated that soil oxygen uptake rates following irradiation, which were higher than expected with eradication of all microbes, were due to enzymatic activity unaffected by the radiation. Enzymes involved may include urease (McLaren et al. 1957, 1962) and respiratory enzymes which remain active in damaged bacterial cells (Peterson 1962). Another effect of radiation at levels similar to those used in this study is reduction of nitrate to nitrite. Following gamma irradiation, the nitrites slowly re-oxidize to nitrates, approximately $60 \%$ of the nitrites having re-oxidized $14 \mathrm{~d}$ after irradiation (Cawse 1975). Further oxygen uptake by sediments, independent of irradiation, takes place during chemical oxidation of metals and sulfides in the sediment (Teal \& Kanwisher 1961, Hayes 1964, Hargrave 1972). In this study portions of the post-irradiation oxygen uptake could be due to any or all of these reactions. Aeration reduced chemical oxygen uptake by providing sufficient oxygen for those reactions to reach an end point (Jakobsen \& Andersen 1982). The high standard error of the mean oxygen consumption rate of the irradiated and aerated samples may stem from variations in the amount of aeration needed for individual sediment samples.

Whether or not all of the microbes were destroyed, the irradiation and aeration treatment of the sediment achieved the desired effect of significantly reducing the sediment oxygen uptake to that of filter-sterilized seawater. This technique is generally applicable to marine sediments, although other sediments may need. different levels of radiation and aeration to achieve a similar reduction in oxygen consumption. Oxygen uptake in marine sands, for example, has been shown to be exclusively biological in origin (Hargrave 1972), which should reduce or eliminate the need for the aeration step. Intact sediment cores which contain macrofauna may require longer periods of irradiation. Once appropriate levels have been found for a particular substrate, this method will be useful for measuring respiration rates of infaunal animals in conditions which more closely approximate those in the natural environment. We have shown that infaunal ophiuroids are able to establish themselves in these treated sediments. This method of respiration measurement would reduce stress on subjects and allow for measurement of respiration rates during apparent normal activity.
Acknowledgements. We thank Dr Don Sens, Sadie B. Greene, Jaqueline LaBreck and especially Mary Rudisill of the Tissue Culture Laboratory at the Medical University of South Carolina. This research was supported by the International Women's Fishing Association Scholarship Trust, a Sigma Xi Grant-in-Aid of Research, the Belle W. Baruch lnstitute of Marine Biology and Coastal Research and the Marine Science Program of the University of South Carolina. This is publication number 1007 of the Belle W. Baruch Institute.

\section{LITERATURE CITED}

Bayne, B. L., Brown, D. A., Burns, K., Dixon, D. R., Ivanovici, A., Livingstone, D. R., Lowe, D. M., Moore, M. N., Stebbing, A.R. D., Widdows, J. (1985). The effects of stress and pollution on marine animals. Praeger, New York

Bayne, B. L., Widdows, J., Newell, R. I. E. (1977). Physiological measurements on estuarine bivalve molluscs in the field. In: Keegan, B. F., Ceidigh, P. O., Boaden, P. J. S. (eds.) Biology of benthic organisms. Pergamon Press, New York, p. $57-68$

Bowen, G. D., Rovira, A. D. (1961). Plant growth in irradiated soil. Nature 191. 936-937

Cawse, P. A. (1975). Microbiology and biochemistry of irradiated soils. In: Paul, E. A., McLaren, A. D. (eds.) Soil biochemistry. Marcel Dekker, Inc., New York, p. 213-267

Dale, T (1978). Total, chemical and biological oxygen consumption of the sediments in Lindaspollene, western Norway. Mar. Biol. 49: 333-341

Davis, R. J., Sheldon, V. L., Auerbach, S. I. (1956). Lethal effects of gamma radiation upon segments of a natural microbial population. J. Bacteriol. 72: 505-510

Dye, A. H. (1983). Oxygen consumption by sediments in a southern African mangrove swamp. Estuar. coast. Shelf Sci. 17: $473-478$

Gofman, J. W. (1981). Radiation and human health. Sierra Club Books, New York

Griffiths, B. S. (1987). Growth of selected microorganisms and plants in soil sterilized by ethylene oxide or gammairradiation. Soil Biol. Biochem. 19: 115-116

Hargrave, B. T (1969). Similarity of oxygen uptake by benthic communities. Limnol. Oceanogr. 14:801-805

Hargrave, B. T (1972). Aerobic decomposition of sediment and detritus as a function of particle surface area and organic content. Limnol. Oceanogr. 17: 583-596

Hayes, F. R. (1964). The mud-water interface. Oceanogr. mar. Biol. A. Rev. 2: 121-145

Jakobsen, I. (1984). Mycorrhizal infectivity of soils eliminated by low doses of ionizing radiation. Soil Biol. Biochem. 16: $281-282$

Jakobsen, I., Andersen, A. J. (1982). Vesicular-arbuscular mycorrhiza and growth in barley: effects of irradiation and heating of soil. Soil Biol. Biochem. 14: 171-178

Josephson, E. S., Peterson, M. S. (1982). Preservation of food by ionizing radiation, Vol. 1. CRC Press, Boca Raton

Lawrence, W. J. C. (1956). Soil sterilization. George Allen \& Unwin, Ltd, Concord, MA

McLaren, A. D. (1969). Radiation as a technique in soil biology and biochemistry. Soil Biol. Biochem. 1. 63-73

M.taren, A. D., Luse, R. A., Skujins, J. J. (1962). Sterilization of soil by irradiation and some further observations on soil enzyme activity. Proc. Soil Sci. Soc. Am. 26: 371-377

McLaren, A. D., Reshetko, L., Huber, W. (1957). Sterilization of soil by irradiation with an electron beam, and some observations on soil enzyme activity. Soil Sci. 83: 497-502

Montagna, P. A., Bauer, J. E., Prieto, M. C., Hardin, D., Spies, 
R. B. (1986). Benthic metabolism in a natural coastal petroleum seep. Mar. Ecol. Prog. Ser. 34: 31-40

Östlund, P., Carmen, R., Edvardsson, U. G. (1989). Sterilization of sediments by ionizing radiation. Appl. Geochem. 4 : 99-103

Pamatmat, M. M. (1977). Benthic community metabolism: a review and assessment of present status and outlook. In: Coull, B. C. (ed.) Ecology of marine benthos. Univ. of South Carolina Press, Columbia, p. 89-111

Peterson, G. H. (1962). Respiration of soil sterilized by ionizing radiation. Soil Sci. 94: 71-74

Powlson, D. S., Jenkinson, D. S. (1976). The effects of biocidal treatments on metabolism in soil. II. Gamma irradiation,

This note was presented by F. J. Vernberg, Columbia,

S. Carolina, USA autoclaving, air drying and fumigation. Soil Biol. Biochem. 8: $179-188$

Sansone, F. J., Andrew, C. C., Okamoto, M. Y. (1987). Adsorption of short-chain organic acids onto nearshore manne sediments. Geochim. Cosmochim. Acta 51: 1889-1896

Skou, J. P. (1962). Studies on the microflora of soil under chronic irradiation. J. gen. Microbiol. 28: 521-530

Sokal, R. R., Rohlf, F. J. (1981). Biometry. W. H. Freeman and Co., San Francisco

Teal, J. M., Kanwisher, J. (1961). Gas exchange in a Georgia salt marsh. Limnol. Oceanogr. 6: 388-399

Urbain, W. M. (1986). Food irradiation. Academic Press, Inc., Orlando

Manuscript first received: December 9, 1992

Revised version accepted: April 8, 1994 